\title{
The Aboriginal and Torres Strait Islander smoking epidemic: what stage are we at, and what does it mean?
}

\section{Raymond Lovetta,d, Katherine A Thurbera and Raglan Maddox ${ }^{b, c}$}

a National Centre for Epidemiology and Population Health, Research School of Population Health, The Australian National University, Canberra, ACT

b Well Living House, Centre for Urban Health Solutions, Li Ka Shing Knowledge Institute, St Michael's Hospital, Toronto, Canada

c Faculty of Health, University of Canberra, ACT, Australia

d Corresponding author: raymond.lovett@anu.edu.au

\section{Article history}

Publication date: October 2017

Citation: Lovett R, Thurber KA, Maddox R. The Aboriginal and Torres Strait Islander smoking epidemic: what stage are we at, and what does it mean? Public Health Res Pract. 2017;27(4):e2741733. https://doi.org/10.17061/phrp2741733

\section{Key points}

- Data limitations restrict our ability to precisely predict trends in Aboriginal and Torres Strait Islander tobacco use and associated health outcomes

- Despite substantial reductions in smoking prevalence, smoking-attributable mortality is likely to remain high because of the long lag time between smoking behaviour and the onset of tobacco-related cancer mortality; this should not be interpreted as a lack of progress in reducing tobacco use and associated harms

- Reducing tobacco use requires a continued comprehensive approach to tobacco control, incorporating Indigenous leadership and long-term investment

\section{Abstract}

Smoking is the leading contributor to the burden of disease among Aboriginal and Torres Strait Islander Australians, and there is considerable potential for change. Understanding the epidemic stage may provide insight into probable trends in smoking-attributable mortality, and inform program and policy development. Tobacco use among Aboriginal and Torres Strait Islander Australians has declined substantially, accompanied by declining tobaccorelated cardiovascular mortality. Based on the available evidence, we expect tobacco-related cancer mortality to remain high, but peak within the next decade; however, there is a critical need for improved evidence to make an accurate assessment. The continuation and expansion of comprehensive tobacco reduction measures is expected to further decrease tobacco use. Health gains will be observed over both the short and long term.

\section{Background}

Cigarette smoking is a leading contributor to the burden of morbidity and mortality among Aboriginal and Torres Strait Islander (hereafter respectfully referred to as Indigenous) Australians ${ }^{1}$, the total Australian population ${ }^{2}$, and in developed countries worldwide. ${ }^{3}$ The health impacts of smoking vary by smoking duration and intensity, but it is well established that smoking causes a range of health conditions. ${ }^{3}$ Although there have been marked smoking reductions in Australia ${ }^{4,5}$, the prevalence of smoking among Indigenous adults remains high, estimated at $41.4 \%$, compared with $14.5 \%$ in the total Australian adult population. ${ }^{5}$

Smoking behaviour is influenced by factors including social, cultural and environmental factors, and tobacco control effectiveness. ${ }^{6}$ Indigenous tobacco use is also tightly tied to Australia's history of colonisation; for example, tobacco was often used as a form of payment, and was issued as part of rations on mission stations. ${ }^{7}$ 
Dramatic decreases in smoking prevalence in the total Australian population suggest that the smoking epidemic is in its final stages. ${ }^{3,6}$ However, the stage of the tobacco epidemic among the Indigenous Australian population is less clear. Understanding the stage of the epidemic provides insight into probable trends in smoking-attributable mortality, thereby enabling accurate communication of the likely impacts of smoking ${ }^{4}$, and informing relevant programs and policies.

This paper provides a perspective on the current stage of the smoking epidemic among Indigenous Australians based on an existing model of smoking epidemic stages ${ }^{3}$, and describes the expected short- and long-term implications for the wellbeing of the Indigenous population, and for programs and policies.

\section{Stages of the smoking epidemic}

Lopez proposed a four-stage model of cigarette consumption and mortality in 1994, characterising features of the smoking epidemic ${ }^{3}$; the model was updated in 2012. ${ }^{4}$ The proportion of the adult population that regularly smokes - and variation by characteristics such as age and sex - provides an indication of the extent to which smoking has been adopted by a population. ${ }^{3}$ Smoking-attributable mortality, which can be crudely approximated by lung cancer deaths, provides insight into the health consequences of smoking at each stage of the epidemic. ${ }^{3,4}$ Central to the model is the long delay between smoking and its associated cancer mortality; even when the prevalence of smoking begins to decline, smoking-attributable mortality continues to increase, reflecting the smoking behaviours of up to three decades earlier. ${ }^{3,4}$

In short, Stage 1 of the tobacco epidemic marks the initial population uptake of smoking, with no evidence of smoking-attributable mortality. In Stage 2, the prevalence of smoking increases rapidly to its peak, alongside low but increasing smoking-attributable mortality. By Stage 3, awareness of the health hazards of smoking is common, and conditions are favourable for implementing tobacco control measures; while the prevalence of smoking remains stable or begins to decrease, smoking-attributable mortality rises rapidly. Stage 4 is represented by decreasing smoking prevalence and associated mortality to their lower limits, in a context of widespread awareness of tobacco harms and tobacco control measures. . $^{3,4}$

\section{Stage of the Indigenous tobacco epidemic}

\section{Prevalence}

Data from national surveys indicate that smoking prevalence (including daily and less frequent) among
Indigenous adults was 54.5\% (95\% Cl 51.7, 57.4) in 1994 and $52.1 \%(95 \% \mathrm{Cl} 49.9,54.3)$ in $2004-05^{8}$, and the prevalence of daily smoking was $50.0 \%(95 \% \mathrm{Cl}$ $47.9,52.2)$ in $2004-05$ and $41.4 \%(95 \%$ Cl 39.1, 43.6) in 2014-15. ${ }^{5}$ It is not possible to determine peak smoking prevalence because of differences in definitions used and the absence of reliable prevalence data before 1994.

Daily smoking prevalence in 2004-05, 2008, 2012 and 2014-15 was similar for Indigenous males and females: a unique feature of this tobacco epidemic. Smoking prevalence trends from 2004 to 2015 vary by remoteness, with daily smoking prevalence decreasing significantly in urban/regional areas (from 49.3\%; $95 \% \mathrm{Cl}$ $46.5,52.1$, to $39.1 \%$; $95 \% \mathrm{Cl} 36.4,41.9)$ but not in remote areas (from 51.9\%; 95\% Cl 48.6, 55.3, to 49.3\%; 95\% Cl 45.3, 53.2). ${ }^{5}$ Although these data may indicate that the tobacco epidemic is at a different stage in urban/regional versus remote settings ${ }^{8}$, particularly for females ${ }^{5}$, we note that the confidence intervals around all estimates are wide, and therefore the data may be underpowered to detect small differences between groups, particularly in remote areas. ${ }^{5,8}$

\section{Smoking-attributable mortality}

There is contemporary direct evidence on smokingattributable mortality among adults in the total Australian population. ${ }^{6}$ However, there is a lack of direct evidence specific to the Indigenous population. Studies have indirectly estimated the impact of smoking on mortality among Indigenous Australians using the aetiologic fractions method ${ }^{9,10}$ and modelling approaches (applying estimates from other populations on the relationship between smoking and lung cancer mortality). ${ }^{11}$ The accuracy of these estimates is unclear.

Although we assume that biological mechanisms underlying smoking-related mortality are similar among Indigenous and non-Indigenous Australians, we acknowledge that the association between smoking and mortality can vary between population subgroups and over time. ${ }^{11-13}$ Contemporary evidence on smokingattributable mortality specific to the Indigenous population is therefore critical to enable accurate communication of the health risks of smoking - and the benefits of not smoking.

Lung cancer mortality can be used as an index of smoking-attributable mortality. ${ }^{3,4}$ However, the existing data are insufficient to enable a detailed examination of trends in lung cancer mortality over time because of factors including underascertainment and misclassification of Indigenous status, and variation in data quality between jurisdictions. ${ }^{14,15}$ Despite this, studies have consistently found that the burden of lung cancer mortality appears at younger ages among Indigenous Australians compared with non-Indigenous Australians. ${ }^{7,10,16-18}$ The reasons for this are unclear, but may include tobacco uptake at earlier ages in the Indigenous population, higher smoking intensity, or 
differences in the age distribution and average life expectancy of the two populations. ${ }^{16}$ Further research is required to understand what underlies this excess mortality in the younger age groups, and to accurately predict the burden of smoking-related mortality in this population.

\section{Awareness of health hazards of tobacco}

Evidence indicates that there is widespread awareness of tobacco-related health consequences among Indigenous Australians, with variation by region and between specific health conditions. ${ }^{7,19}$ However, this widespread awareness is not necessarily associated with intention to quit or reduce smoking. ${ }^{7}$

\section{Implications for future smoking- related health burden}

The model suggested by Lopez does not precisely fit the tobacco epidemic among Indigenous Australians (e.g. the extended duration of the epidemic, high smoking prevalence among females, and variation between urban/ regional and remote settings). Regardless, the model provides a useful framework for considering smoking trends and implications.

Overall, the available data suggest that the Indigenous population is at an earlier stage of the tobacco epidemic than the total Australian population, at Stage 3 versus Stage 4. ${ }^{3,4}$ Differences in smoking prevalence trends by remoteness and sex suggest that the stage of the epidemic, and therefore associated mortality trends, may vary between groups. However, we caution that the largest contemporary datasets are insufficient to enable precise assessment of trends within subgroups. ${ }^{5}$

Despite the lack of data to accurately quantify smoking-attributable mortality within the Indigenous population, available data indicate that the burden of smoking-attributable mortality is likely to remain high. The burden of tobacco-related cardiovascular disease is likely to continue to decline in the short term as smoking prevalence continues to decline. The burden of lung cancer may peak within the next decade, based on the assumption that peak smoking prevalence occurred at or before 1994 (Figure 1). ${ }^{15}$ This reflects the long lag time between smoking behaviour and the onset of tobaccorelated cancer mortality; this should not be interpreted as a lack of progress in reducing tobacco use and associated harms. This is supported by findings that the burden of tobacco-related cardiovascular diseases among Indigenous people decreased between 2003 and 2011, while the burden of tobacco-related cancer and respiratory disease increased. ${ }^{1}$

It is important to consider that, even if there is a decrease in the absolute rate of smoking-attributable mortality, the relative proportion of all deaths that are attributable to smoking may continue to increase if mortality rates attributed to other causes (not related to smoking) decrease. ${ }^{20}$ To capture changes in the health burden associated with smoking within the Indigenous population, we need evidence about smoking-attributable mortality in both absolute and relative terms.

\section{Implications for tobacco control}

Several data gaps need to be addressed to ensure appropriate monitoring of the Indigenous tobacco epidemic, including precise estimates of smokingattributable mortality and smoking prevalence, to enable monitoring of changes over time.

Regardless, the health consequences of smoking are well established. The earlier in life people quit smoking, the larger the expected health benefits. ${ }^{6}$ With an estimated 165000 current Indigenous daily smokers ${ }^{5}$, the implementation of effective, appropriate and sustained tobacco control measures and programs is required to prevent substantial numbers of premature deaths. ${ }^{3}$ These efforts will need to consider variation in smoking behaviours - and their underlying determinants - by age, sex and remoteness. ${ }^{21}$

The Framework Convention on Tobacco Control provides substantial guidance on Indigenous participation in developing, implementing and evaluating socially and culturally appropriate tobacco control. ${ }^{22}$ This aligns with and complements a comprehensive approach to gender-inclusive tobacco control, encompassing a suite of Indigenous-specific tobacco reduction measures across urban, regional and remote settings. Further, the incorporation of Indigenous leadership, long-term investment and the provision of culturally appropriate materials and activities is critical to further reducing tobacco use. ${ }^{19,23-25}$

\section{Conclusion}

Smoking is the leading contributor to the burden of disease among Indigenous Australians. ${ }^{1}$ Reducing the prevalence of smoking is critical and will generate substantial health gains. To precisely assess progress in reducing smoking prevalence among Indigenous Australians, better data are required.

Our assessment, based on the available evidence, is that the Indigenous tobacco epidemic is at Stage 3 of the Lopez model. We expect to see steadily declining tobacco-related cardiovascular mortality, and expect that tobacco-related cancer mortality will remain high but peak within the next decade. This stage requires continuation and extension of the suite of comprehensive tobacco reduction programs and policies to assist in accelerating declines in tobacco use, contributing to health benefits.

Understanding the stage of the Indigenous tobacco epidemic enables community members, researchers and policy makers to better interpret mortality trends in 
Figure 1. Estimated timeline of tobacco control measures, prevalence of tobacco use and associated health impacts

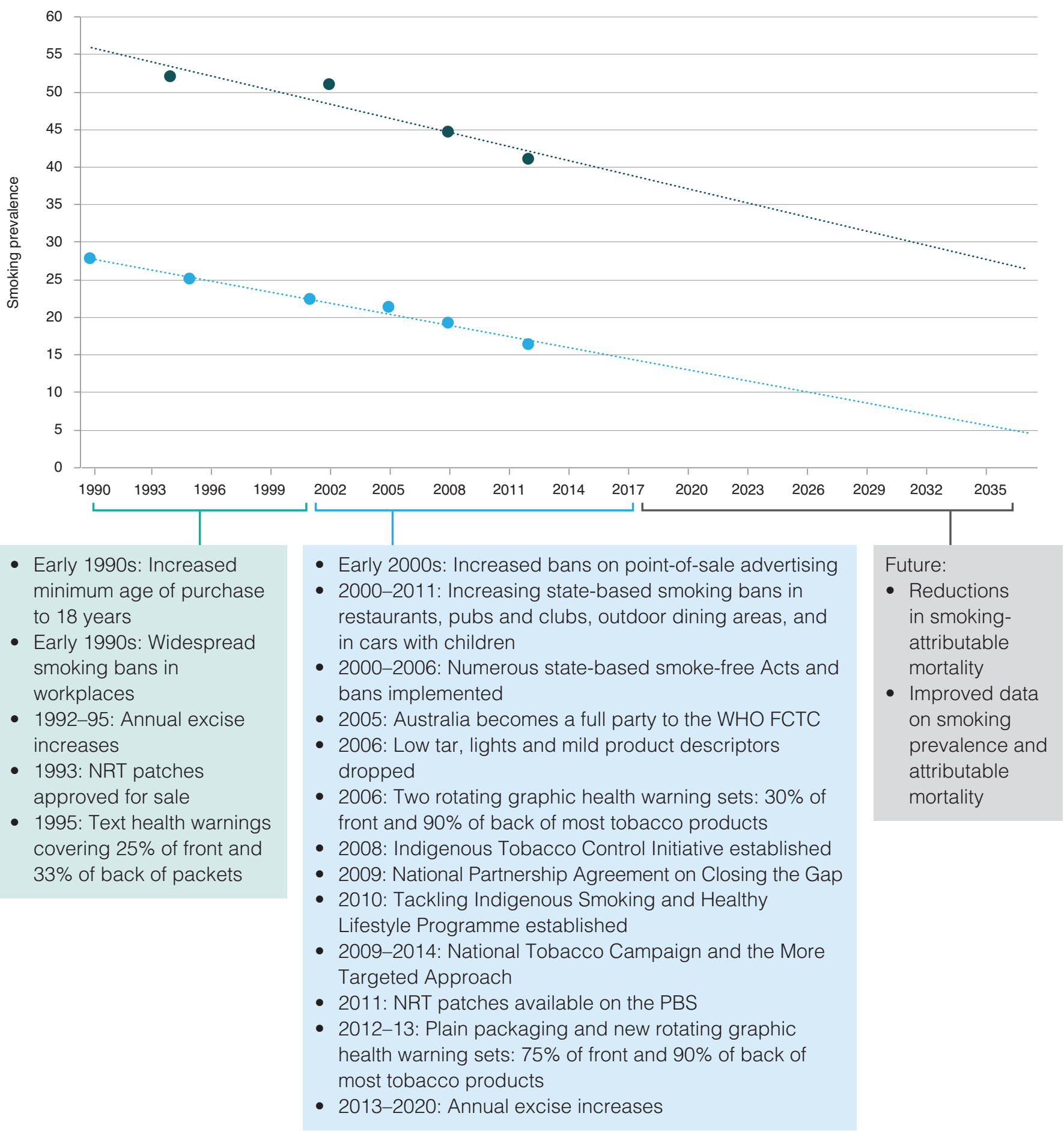

Australian smoking prevalence (\%)

Aboriginal and Torres Strait Islander smoking prevalence (\%)

NRT = nicotine replacement therapy; PBS = Pharmaceutical Benefits Scheme; WHO FCTC = World Health Organization Framework Convention on Tobacco Control 
the short and long term, informing evaluation of tobacco control programs and the assessment of progress made in reducing tobacco use.

\section{Acknowledgements}

$\mathrm{RL}$ is supported by a National Health and Medical

Research Council Fellowship.

\section{Competing interests}

None declared

\section{Author contributions}

$\mathrm{RL}$ and $\mathrm{KT}$ conceived the manuscript. $\mathrm{RL}, \mathrm{KT}$ and $\mathrm{RM}$ drafted the manuscript and provided comments on all drafts of the manuscript. All authors read and approved the final version.

\section{References}

1. Australian Institute of Health and Welfare. Australian Burden of Disease Study: impact and causes of illness and death in Aboriginal and Torres Strait Islander people 2011. Canberra: AlHW; 2016 [cited 2017 Sep 3]. Available from: www.aihw.gov.au/getmedia/e31976fcadcc-4612-bd08-e54fd2f3303c/19667-bod7-atsi-2011. pdf.aspx?inline $=$ true

2. Australian Institute of Health and Welfare. Australian Burden of Disease Study: impact and causes of illness and death in Australia 2011. Canberra: AlHW; 2016 [cited 2017 Sep 3]. Available from: www.aihw.gov.au/getmedia/ d4df9251-c4b6-452f-a877-8370b6124219/19663.pdf. aspx?inline $=$ true

3. Lopez AD, Collishaw NE, Piha T. A descriptive model of the cigarette epidemic in developed countries. Tob Control. 1994;3(3):242-47.

4. Thun M, Peto R, Boreham J, Lopez AD. Stages of the cigarette epidemic on entering its second century. Tob control. 2012;21(2):96-101.

5. Lovett R, Thurber KA, Wright A, Maddox R, Banks E. Deadly progress: changes in Australian Aboriginal and Torres Strait Islander adult daily smoking from 20042015. Under review.

6. Banks E, Joshy G, Weber MF, Liu B, Grenfell R, Egger S, et al. Tobacco smoking and all-cause mortality in a large Australian cohort study: findings from a mature epidemic with current low smoking prevalence. BMC Med. 2015;13(1):38.

7. Scollo M, Winstanley M, editors. Tobacco in Australia: facts and issues. Melbourne: Cancer Council Victoria; 2012 [cited 2017 Sep 3]. Available from: www.tobaccoinaustralia.org.au
8. Thomas DP. Smoking prevalence trends in Indigenous Australians, 1994-2004: a typical rather than an exceptional epidemic. Int J Equity Health. 2009;8(1):1.

9. Unwin CE, Gracey MS, Thomson NJ. The impact of tobacco smoking and alcohol consumption on Aboriginal mortality in Western Australia, 1989-1991. Med J Aust. 1995;162(9):475-8.

10. Measey M-A, d'Espaignet E, Cunningham J. Adult morbidity and mortality due to tobacco smoking in the Northern Territory, 1986-1995. Darwin: Territory Health Services; 1998 [cited 2017 Sep 3]. Available from: digitallibrary.health.nt.gov.au/ dspace/bitstream/10137/109/1/mortality_morbidity_ smoking_1986.pdf

11. Hunt D, Blakely T, Woodward A, Wilson N. The smokingmortality association varies over time and by ethnicity in New Zealand. Int J Epidemiol. 2005;34(5):1020-8.

12. Carter KN, Blakely T, Soeberg M. Trends in survival and life expectancy by ethnicity, income and smoking in New Zealand: 1980s to 2000s. N Z Med J. 2010;123.

13. Wardman D, Khan NA. Smoking-attributable mortality among British Columbia's First Nations populations. Int J Circumpolar Health. 2004;63(1):81-92.

14. Zhang X, Condon J, Dempsey K, Garling L. Cancer incidence and mortality, Northern Territory, 1991-2005. Darwin: Department of Health and Families; 2008.

15. Vos T, Barker B, Stanley L, Lopez A. The burden of disease and injury in Aboriginal and Torres Strait Islander peoples 2003. Brisbane: School of Population Health, University of Queensland; 2007 [cited 2017 Sep 3]. Available from: www.lowitja.org.au/sites/default/files/docs/ Indigenous-BoD-Policy-Brief.pdf

16. Condon JR, Barnes T, Cunningham J, Armstrong BK. Long-term trends in cancer mortality for Indigenous Australians in the Northern Territory. Med J Aust. 2004;180(10):504-7.

17. Cunningham J, Rumbold AR, Zhang X, Condon JR. Incidence, aetiology, and outcomes of cancer in Indigenous peoples in Australia. Lancet Oncol. 2008;9(6):585-95.

18. Australian Institute of Health and Welfare. Cancer in Aboriginal and Torres Strait Islander peoples of Australia: an overview. Canberra: AlHW; 2013 [cited 2017 Sep 3]. Available from: www.aihw.gov.au/getmedia/ aa938fd4-21e8-4854-9207-c70306e4f2b3/13732.pdf. aspx?inline $=$ true

19. Nicholson AK, Borland R, Couzos S, Stevens M, Thomas DP. Smoking-related knowledge and health risk beliefs in a national sample of Aboriginal and Torres Strait Islander people. Med J Aust. 2015;202(10):S45-50.

20. Blakely T, Carter K, Wilson N, Edwards R, Woodward A, Thomson G, Sarfati D. If nobody smoked tobacco in New Zealand from 2020 onwards, what effect would this have on ethnic inequalities in life expectancy? N Z Med J. 2010;123(1320):26-36. 
21. Greaves L, Pederson A, Hemsing N. International Tobacco Control Policy: the implications of SGBA. In: Clow B, Pederson A, Haworth-Brockman M, Bernier J, editors. Rising to the challenge: sex- and genderbased analysis for health planning, policy and research in Canada. Halifax, Nova Scotia: Atlantic Centre of Excellence for Women's Health; 2009.

22. World Health Organization. WHO Framework Convention on Tobacco Control. Geneva: WHO Document Production Services; 2003 [cited 2017 Sep 3]. Available from: apps. who.int/iris/bitstream/10665/42811/1/9241591013.pdf

23. Minichiello A, Lefkowitz AR, Firestone M, Smylie JK, Schwartz R. Effective strategies to reduce commercial tobacco use in Indigenous communities globally: a systematic review. BMC Pub Health. 2016;16(1):21.
24. Eades SJ, Chamberlain C. Seeking a comprehensive approach to tobacco control for Aboriginal and Torres Strait Islander people. Med J Aust. 2015;202(10):511-2.

25. Nicholson AK, Borland R, Sarin J, Wallace S, van der Sterren AE, Stevens M, Thomas DP. Recall of antitobacco advertising and information, warning labels and news stories in a national sample of Aboriginal and Torres Strait Islander smokers. Med J Aust. 2015;202(10):67-72.

\section{Copyright: (c) (i) (2)}

(c) 2017 Lovett et al. This article is licensed under the Creative Commons Attribution-NonCommercial-ShareAlike 4.0 International Licence, which allows others to redistribute, adapt and share this work non-commercially provided they attribute the work and any adapted version of it is distributed under the same Creative Commons licence terms. See: www.creativecommons.org/licenses/by-nc-sa/4.0/ 